\title{
Multiple HPV-Induced Squamous Cell Carcinomas on the Fingers of a Patient with Systemic Lupus Erythematosus: A Case and Review
}

\author{
Georgios Nikolakis Ioannis Karagiannidis Vasiliki A. Zampeli \\ Andreas Altenburg Martina Brunner Christos C. Zouboulis
}

Departments of Dermatology, Venereology, Allergology and Immunology, Dessau Medical

Center, Dessau, Germany

\section{Key Words}

Human papilloma virus · Lupus erythematosus · Squamous cell carcinoma $\cdot$ HPV-33

\begin{abstract}
Human papilloma virus (HPV) infection is documented to be involved in the development of epithelial malignancies, mostly in cervical cancer. Systemic lupus erythematosus (SLE) patients have an increased prevalence of such an infection. We report the case of a 55-year-old female SLE patient who developed multiple in situ squamous cell carcinomas on her fingers, after chronic HPV infection. HPV-33 DNA was isolated from the lesions. The purpose of this case presentation is to raise awareness about HPV-induced malignancies for this high-risk group and propose an early HPV vaccination to efficiently prevent such comorbidities.
\end{abstract}

\section{Introduction}

Human papilloma virus (HPV) infection is currently considered one of the most prevalent sexually transmitted diseases worldwide, leading to a broad palette of different conditions, ranging from common warts to malignancy. Its involvement in cervical carcinogenesis is well established, since it facilitates the evasion of apoptosis from damaged cervical cells. Multiple risk factors are associated with HPV prevalence, among which is the patient's immunocompetence status [1]. Despite the lack of known risk factors for an HPV infection, 
Nikolakis et al.: Multiple HPV-Induced Squamous Cell Carcinomas on the Fingers of a Patient with Systemic Lupus Erythematosus: A Case and Review

systemic lupus erythematosus (SLE) patients were found to have a 3-fold increase in HPV infection [2]. Furthermore, infection by high-risk HPV subtypes was more frequently reported in SLE patients $[3,4]$.

\section{Case Presentation}

A 55-year-old patient presented to our Departments with chronic, erythematous, eczematous, and hyperkeratotic and partially exophytic skin lesions on her fingers (fig. 1). The 2nd finger of the left hand (fig. 1a) and fingers D1-D5 (fig. 1b-d) of the right hand were affected. The lesions observed on the 4th finger of the right hand showed exudative ulceration and nail loss (fig. 1c). The patient underwent a 3-week treatment with fusidic acid and hydrocortisone cream, which did not improve the lesions. The patient was diagnosed with SLE, involving sicca and Raynaud symptoms, arthralgias, and the characteristic butterfly rash, about 20 years ago. Routine laboratory parameters were in the normal range except for lymphocytes 6.3\% (range 16-39), neutrophils 82.9\% (range 51-74), C-reactive protein 14 $\mathrm{mg} / \mathrm{l}$ (range 0-5), and GFR-K $67.2 \mathrm{ml} / \mathrm{min}$ (range 80-140). Laboratory tests regarding the immunological status are presented: antinuclear antibodies 1:1,280; extractable nuclear antigens, negative; $\mathrm{C}_{3}$ complement $1.02 \mathrm{~g} / \mathrm{l}$ (range 0.9-1.8); $\mathrm{C}_{4}$ complement $0.274 \mathrm{~g} / \mathrm{l}$ (range 0.1-0.4); double-stranded DNA antibodies, positive (1:80), and circulating immune complexes, normal. The patient was under treatment with hydroxychloroquine $200 \mathrm{mg}$ daily and $5 \mathrm{mg}$ prednisolone, alternating every other day with $10 \mathrm{mg}$.

A comprehensive history revealed the removal of bowenoid papulosis by electrocautery from the anogenital and vaginal region 17 years ago. The patient also suffered from perianal condylomata acuminata, removed in 2001 and 2010. Virus typing resulted in the isolation of HPV-6 DNA. Furthermore, 20 years ago, she underwent a total hysterectomy because of a cervical in situ carcinoma.

Swab tests from the right finger D4 were positive for Enterococcus faecalis, ciprofloxacin sensitive as well as positive for Candida parapsilosis. The infection was treated with ciprofloxacin $250 \mathrm{mg}$ twice daily for 10 days and the mycosis with ciclopirox cream twice daily for 3 weeks. An X-ray of the same digit revealed no destruction of the bony tissue and no signs of osteomyelitis.

A punch biopsy from the left finger D2 revealed a widened epithelium with impaired strata formation. Polymorphic cells and nuclei were observed, together with numerous and atypical mitoses (fig. 2a). Immunohistochemistry against the proliferation marker Ki-67 resulted in positive staining of about $60 \%$ of the epidermis. No invasion of the proliferating keratinocytes through the basal membrane was reported. These findings were compatible with the diagnosis of a squamous cell carcinoma in situ, or Bowen's disease. Two biopsies from the fingers D2 and D4 of the right hand were subsequently performed with identical histological patterns.

After confirmation of the diagnosis, two cycles of photodynamic therapy after previous application of methyl-5-amino-4-oxopentanoate cream were performed without significant improvement in the lesions. Three months after treatment, multiple erosions and ulcerations of the 4th finger of the right hand were present (fig. 2c, d). New biopsies once more confirmed Bowen's disease, whereas clumping cells, koilocytes, focal hypergranulosis, and irregular keratohyalin granules with focal condensation were compatible with a virus infection (fig. 2b). DNA was isolated from the paraffin blocks of the lesional biopsies (QIAamp DNA FFPE Tissue Kit; QIAGEN GmbH, Hilden, Germany). HPV typing was performed through a sensitive line probe assay (INNO-LiPA HPV Genotyping Extra; Innogenetics, Gent, Belgium), 
Nikolakis et al.: Multiple HPV-Induced Squamous Cell Carcinomas on the Fingers of a Patient with Systemic Lupus Erythematosus: A Case and Review

using the principle of reverse hybridization. Through detection of specific sequences of the L1 region of the HPV genome, 28 HPV subtypes and, specifically, 15 high-risk subtypes can be identified. In our case, DNA from the high-risk HPV-33 was detected.

After confirmation of the HPV infection as a cause for the in situ squamous cell carcinomas, imiquimod $5 \%$ was initiated. The therapy led to partial remission of the lesions but had to be stopped because of the intense local reaction on the finger D4 of the right hand. Ingenol mebutate gel $500 \mu \mathrm{g} / \mathrm{g}$ was used off-label for the lesions over 2 days. The therapy led to further remission of the lesions, after their assessment 1 month after therapy.

After 3 months, the patient was treated with $\mathrm{CO}_{2}$ laser ablation and curettage in intubation anesthesia at an external department. She received cefuroxim $500 \mathrm{mg}$ twice daily for 10 days, metamizole drops for postinterventional analgesia, and local therapy, initially with povidone iodine gauzes, disinfection with a polyhexanide-containing solution (Sanalind ${ }^{\circledR}$ ), and subsequently with polyhexanide in cetearyl alcohol and petrolatum-coated nonadherent gauzes $\left(\right.$ Adaptic $^{\circledR}$ ). The fibrinous layers which remained were efficiently removed with Debrisoft ${ }^{\circledR}$. Follow-up biopsies 2 months after treatment showed no tumor residues (fig. 2e, f).

\section{Discussion}

This is, to the best of our knowledge, the first case reporting multiple HPV-induced in situ squamous cell carcinomas in an SLE patient at this location. HPV-33 is a high-risk subtype for cervical dysplasia. HPV-11 DNA was isolated from a patient with multiple squamous cell carcinomas and nonscarring cutaneous LE [5], while a squamous cell carcinoma was reported in an SLE patient with discoid LE [6]. Most of the clinical studies, prospective and retrospective, were conducted to provide evidence for a correlation between SLE and HPVinduced cervical dysplasia or cancer. Furthermore, HPV-related anal carcinomas were documented for SLE patients under treatment with cyclophosphamide [7].

A recent Danish study of 576 SLE patients investigated the risk of virus-associated malignancies for this patient cohort. Interestingly, as far as HPV-associated malignant and premalignant conditions are concerned, SLE patients were found to have an increased risk of anal cancer, cervix dysplasia/in situ carcinoma, and melanoma skin cancer (standardized incidence ratio $2.0,95 \%$ confidence interval 1.2-3.6) [8].

The pathophysiology of this susceptibility is not yet elucidated. Healthy immune response to HPV includes the production of specific antibodies and a cell-mediated response after Th1-lymphocyte activation [9]. Patients with SLE are known to have impairments of both cellular and innate immunity, which lead to difficulty in clearing high-risk HPV. Possible mechanisms also include complement deficiency, IgG subclass deficiency, and cytokine receptor polymorphisms [3]. A recent study showed an impairment of Toll-like receptor (TLR) regulation in SLE patients compared to controls with HPV infection. Those patients had significantly lower levels of TLR3 and TLR7 in comparison to controls. HPV-infected SLE patients had lower levels of TLR7 and TLR9, thus facilitating viral persistence [10].

Immunosuppressive agents are involved in the persistence of HPV infection by inhibition of innate immune responses, which are involved in containing the virus [2]. Studies, which have demonstrated a significant correlation between cervical dysplasia in SLE patients who had previously received azathioprine, cyclophosphamide (positive association with duration and cumulative dose), and mycophenolate mofetil, are reported in the literature $[9,11]$. Mycophenolate mofetil was shown to reduce the number of B cells and natural killer cells in SLE patients, thus enhancing the risk of an HPV infection [9]. Interestingly, the 
Nikolakis et al.: Multiple HPV-Induced Squamous Cell Carcinomas on the Fingers of a Patient with Systemic Lupus Erythematosus: A Case and Review

use of immunosuppressive drugs was not always associated with a higher prevalence of HPV infection, probably because of an inadequate number of cases analyzed or controls [2, 3, 12, 13]. In the study of Klumb et al. [2], SLE patients with mild or no immunosuppressant use were more often diagnosed with an HPV infection, although the difference was not statistically significant. Chronic use of prednisolone and the TLR antagonist hydroxychloroquine, which were also used for the treatment of the patient presented, can decrease TLR7 and TLR9 at the protein level, providing the rationale for a further decrease in the immune response against such a viral infection [10].

\section{Conclusion}

Since up to $80 \%$ of the female population is predicted to encounter an HPV infection in the first 50 years of their life, early routine vaccination of high-risk patients (routinely before the 11th-12th year of age), such as SLE patients, is of great importance. Both the bivalent and quadrivalent vaccines are composed of noninfectious virus-like particles, which induce an effective T-cell-dependent B-cell response, thus producing high levels of L1-specific neutralizing antibodies and T-cell memory [2]. Recently, a 9-equivalent vaccine was introduced to the market and is recommended for females aged 13-26 years and males aged 13-21 years not previously vaccinated [14]. At the other end of the spectrum, manifestations of SLE or SLE-like symptoms, particularly for patients with a personal or family history of SLE, after vaccination against the HPV virus have recently been reported [15]. Despite this, HPV vaccination of SLE patients might be the most plausible and cost-effective approach to sufficiently control this infection and the consequent development of HPV-induced malignancies.

\section{Statement of Ethics}

All photos presented in this case report were taken after the patient's informed consent. All photos were taken in the outpatient clinic of the Departments of Dermatology, Venereology, Allergology and Immunology of Dessau Medical Center, Dessau, Germany.

\section{Disclosure Statement}

The authors have no conflicts of interest to declare.

\section{References}

1 Bosch FX, Lorincz A, Muñoz N, Meijer CJLM, Shah KV: The causal relation between human papillomavirus and cervical cancer. J Clin Pathol 2002;55:244-265.

-2 Klumb E, Pinto A, Jesus G, Araujo M, Jascone L, Gayer C, Ribeiro F, Albuquerque E, Macedo J: Are women with lupus at higher risk of HPV infection? Lupus 2010;19:1485-1491.

-3 Tam LS, Chan AY, Chan PK, Chang AR, Li EK: Increased prevalence of squamous intraepithelial lesions in systemic lupus erythematosus: association with human papillomavirus infection. Arthritis Rheum 2004;50:3619-3625.

-4 Blumenfeld Z, Lorber M, Yoffe N, Scharf Y: Systemic lupus erythematosus: predisposition for uterine cervical dysplasia. Lupus 1994;3:59-61.

-5 Cohen LM, Tyring SK, Rády P, Callen JP: Human papillomavirus type 11 in multiple squamous cell carcinomas in a patient with subacute cutaneous lupus erythematosus. J Am Acad Dermatol 1992;26:840845. 


\section{Case Reports in Dermatology}

Nikolakis et al: Multiple HPV-Induced Squamous Cell Carcinomas on the Fingers of a Patient with Systemic Lupus Erythematosus: A Case and Review

6 Simpson JK, Medina-Flores R, Deng JS: Squamous cell carcinoma arising in discoid lupus erythematosus lesions of the ears infected with human papillomavirus. Cutis 2010;86:195-198.

-7 Lydon E, Belmont H: When rectal bleeding is serious: anal squamous cell carcinoma in two intravenous cyclophosphamide treated systemic lupus erythematosus patients with human papilloma virus infection. Lupus 2013;22:1182-1184.

-8 Dreyer L, Faurschou M, Mogensen M, Jacobsen S: High incidence of potentially virus-induced malignancies in systemic lupus erythematosus: a long-term follow-up study in a Danish cohort. Arthritis Rheum 2011;63:3032-3037.

-9 Abud-Mendoza C, Cuevas-Orta E, Santillan-Guerrero EN, Martinez-Martinez MU, Hernandez-Castro B, Estrada-Capetillo L, Gonzalez-Amaro R, Baranda L: Decreased blood levels of B lymphocytes and NK cells in patients with systemic lupus erythematosus (SLE) infected with papillomavirus (HPV). Arch Dermatol Res 2013;305:117-123.

10 Yu SL, Chan PK, Wong CK, Szeto CC, Ho SC, So K, Yu MM, Yim SF, Cheung TH, Wong MC, Cheung JL, Yeung AC, Li EK, Tam LS: Antagonist-mediated down-regulation of Toll-like receptors increases the prevalence of human papillomavirus infection in systemic lupus erythematosus. Arthritis Res Ther 2012;14:R80.

$\checkmark 11$ Tam LS, Chan PK, Ho SC, Yu MY, Yim SF, Cheung TH, Wong MC, Cheung JL, Li EK: Risk factors for squamous intraepithelial lesions in systemic lupus erythematosus: a prospective cohort study. Arthritis Care Res (Hoboken) 2011;63:269-276.

12 Berthier S, Mougin C, Vercherin P, Desmurs H, Gil H, de Wazieres B, Dupond JL: Does a particular risk associated with papillomavirus infections exist in women with lupus? Rev Med Interne 1999;20:128-132.

-13 Nath R, Mant C, Luxton J, Hughes G, Raju KS, Shepherd P, Cason J: High risk of human papillomavirus type 16 infections and of development of cervical squamous intraepithelial lesions in systemic lupus erythematosus patients. Arthritis Rheum 2007;57:619-625.

14 Petrosky E, Bocchini JA Jr, Hariri S, Chesson H, Curtis CR, Saraiya M, Unger ER, Markowitz LE: Use of 9-valent human papillomavirus (HPV) vaccine: updated HPV vaccination recommendations of the advisory committee on immunization practices. MMWR Morb Mortal Wkly Rep 2015;64:300-304.

15 Gatto M, Agmon-Levin N, Soriano A, Manna R, Maoz-Segal R, Kivity S, Doria A, Shoenfeld Y: Human papillomavirus vaccine and systemic lupus erythematosus. Clin Rheumatol 2013;32:1301-1307.
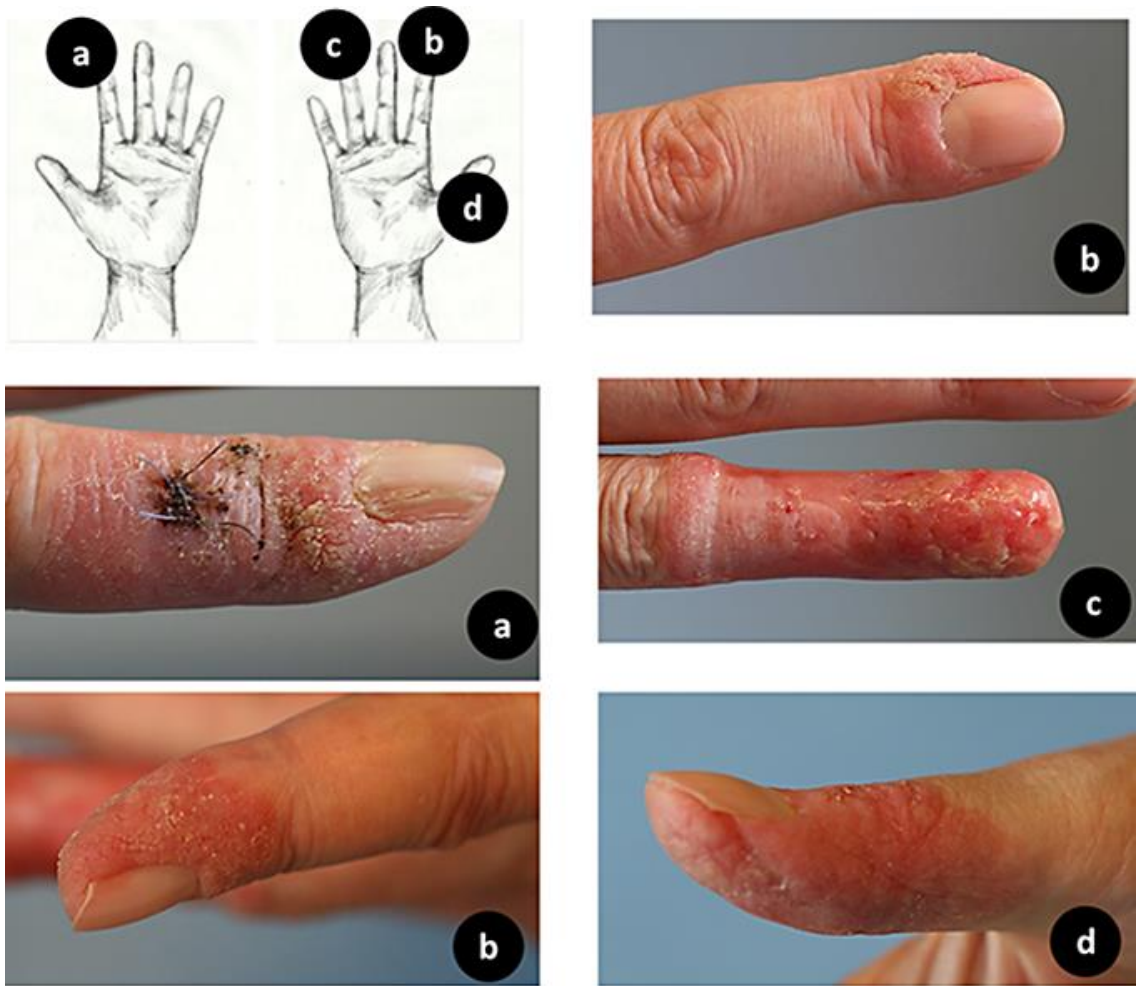

Fig. 1. Skin manifestations on fingers D1 (d), D2 (b) and D4 (c) of the right hand and the second finger (D2) of the left hand (a) during the first presentation of the patient to our Departments. 


\section{Case Reports in Dermatology}
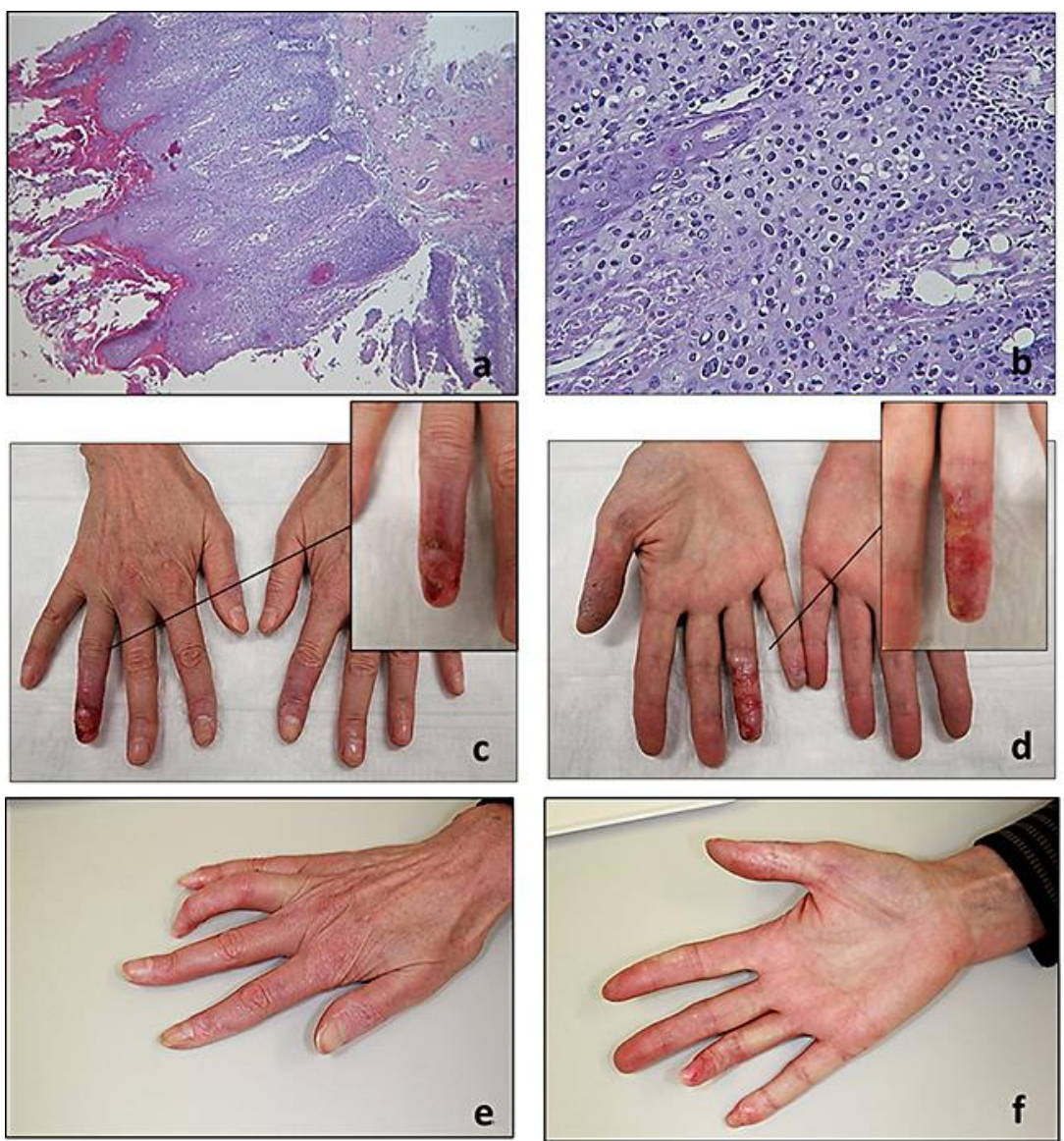

Fig. 2. a Histological examination of the lesions revealed impaired stratification, cell and nucleus polymorphy and atypical mitoses. b Koilocytes and irregular keratohyalin granules, suggesting HPV infection. c, d 3 months after therapy, multiple erosions and ulcerations of D4 of the right hand were still present. e, $\mathbf{f}$ Clinical result 8 months after last treatment of the lesions with $\mathrm{CO}_{2}$ laser ablation 